\title{
A participação das mulheres no mercado de trabalho sob a perspectiva da teoria da justiça social de Nancy Fraser e dos conceitos relativos ao trabalho decente
}

\author{
Claudia Borges Colcerniani, Maria Inácia D’Ávila Neto, \\ Cláudio de São Thiago Cavas ${ }^{1}$ \\ Universidade Federal do Rio de Janeiro (Rio de Janeiro, RJ, Brasil)
}

\begin{abstract}
A crescente inserção das mulheres no mercado de trabalho tem evidenciado questões importantes, especialmente nos âmbitos social, político e econômico. Nesse contexto, há dificuldades expressivas enfrentadas pelas mulheres trabalhadoras, essencialmente caracterizadas por situações de preconceito, discriminação e estereótipos. O presente artigo trata dessas condições da participação feminina no mercado de trabalho e pretende ressaltar a relevância do alcance da justiça social, nos termos propostos pela filósofa norte-americana Nancy Fraser, por intermédio da promoção do trabalho decente e de acordo com os conceitos da Organização Internacional do Trabalho (OIT), agência multilateral da Organização das Nações Unidas (ONU), representada por governos, empregadores e trabalhadores. Cada vez mais, as relações trabalhistas ancoradas em justiça social e trabalho decente, de uma maneira conjunta, proporcionam oportunidades valiosas para o alcance de uma sociedade com igualdade de oportunidades para homens e mulheres.
\end{abstract}

Palavras-chave: Trabalho, Mulheres, Justiça social, Trabalho decente, Organização Internacional do Trabalho.

The participation of women in the labor market under the perspective of social justice by Nancy Fraser and the concepts of decent work

The increasing inclusion of women in the labor market has highlighted important issues, especially in the social, political and economic spheres. In this context, there are expressive difficulties faced by working women, essentially characterized by situations of prejudice, discrimination and stereotypes. The present article deals with these conditions of female participation in the labor market and intends to emphasize the relevance of the reach of social justice, in the terms proposed by the American philosopher Nancy Fraser, through the promotion of decent work and in accordance with the concepts of the International Labour Organization (ILO), a multilateral agency of the United Nations (UN), represented by governments, employers and workers. Increasingly, labor relations anchored in social justice and decent work, in a joint manner, provide valuable opportunities for the achievement of a society with equal opportunities for men and women.

Keywords: Labor, Women, Social justice, Decent work, International Labour Organization.

$\mathrm{D}$ entre os diferentes direitos sociais ${ }^{2}$ previstos constitucionalmente, o trabalho ocupa, sem dúvida, uma posição de expressiva relevância no cenário sociopolítico e econômico. A partir do exercício laboral, grupos sociais diversos encontram oportunidades para o alcance da participação e inclusão social, bem como para o enfrentamento da pobreza.Partindo da ideia de que o trabalho é o melhor programa social a ser oferecido pelo Estado, entendemos que a garantia de acesso ao mercado de trabalho deve ser escopo primordial na elaboração de políticas públicas eficientes e eficazes. Nesse sentido, parte da população, ainda inserida em condições de subalternidade e submissão, encontrará meios para desprender-se do processo de dependência do poder público, firmando-se em um cenário de justiça social. Sob essa perspectiva, encontramos na teoria crítica da socióloga e filósofa norte-americana Nancy Fraser os conceitos relativos à justiça social, ancorada nas bases econômica, cultural e política. A autora entende que tais aspectos, considerados conjuntamente e de maneira integrada, formam o arcabouço da justiça social.

1 Os autores fazem parte do Programa de Pós-Graduação em Psicossociologia de Comunidades e Ecologia Social do Instituto de Psicologia da Universidade Federal do Rio de Janeiro.

2 Nos termos da atual Constituição Federal, artigo 6º , são direitos sociais: a educação, a saúde, a alimentação, o trabalho, a moradia, o lazer, a segurança, a previdência social, a proteção à maternidade e à infância, bem como a assistência aos desamparados. 


\section{A justiça social nos termos propostos por Nancy Fraser}

De acordo com os conceitos de Fraser (2007), no enfrentamento das injustiças podemos nos valer de três tipos de medidas, chamadas por ela de remédios: a redistribuição, no combate à injustiça econômica; o reconhecimento, no caso da injustiça cultural; e a representação, como forma de defrontar a injustiça política.

Dentre uma das formas de redistribuição econômica, está a reorganização do trabalho. Conforme Fraser $(2009,2013)$ propõe, tal medida pode ser considerada transformativa, uma vez que provoca mudanças não apenas nos resultados, mas em toda a estrutura relativa ao exercício laboral, buscando estabelecer relações justas entre trabalhadores, empregadores e poder público, ancoradas no respeito aos direitos humanos e, consequentemente, na valorização de uma vida mais digna.

Nessa perspectiva, podemos afirmar que o princípio da dignidade humana ${ }^{3}$, previsto no artigo primeiro da Constituição Federal, abrange, sem dúvida, o acesso e o exercício do trabalho, e a busca por essa dignidade passa, certamente, pelas oportunidades de trabalho. Essa questão torna-se, cada vez mais, objeto de importantes estudos e discussões em diferentes níveis, tanto em âmbito nacional quanto internacional, extrapolando fronteiras. Vemos, não só no Estado brasileiro, mas em escala global, o crescente número de pessoas buscando melhores condições de vida por intermédio da atividade laboral produtiva.

Um grande número de países tem vivenciado crises profundas que refletem muito diretamente na escassez da oferta de trabalho e, consequentemente, no alargamento da pobreza. Nesse cenário, as injustiças sociais tornam-se cada vez mais evidentes.

A busca por uma vida com qualidade e dignidade humana tem motivado milhares de pessoas a migrar para regiões diversas, seja interna ou externamente ao país onde vivem e, dentre as situações que caracterizam a justiça social, ressaltamos as oportunidades relativas ao exercício do trabalho.

Por essa razão, milhares de indivíduos têm buscado, a qualquer custo, migrar para regiões onde a oferta de trabalho e, consequentemente, de uma vida mais digna e justa seja possível.

Dentre tantos exemplos significativos, citamos, com base em dados publicados pelo Alto Comissariado das Nações Unidas para Refugiados (ACNUR), agência da Organização das Nações Unidas (ONU), a situação de homens e mulheres, de todas as idades, que têm arriscado suas vidas em travessias clandestinas e extremamente arriscadas, na esperança de ter direito de acesso ao mercado de trabalho, à segurança, à saúde, enfim, na busca por uma vida melhor. Síria, Afeganistão, Iraque e Eritreia estão entre os países com o maior número de emigrantes, nos quais a violência, as guerras e a pobreza têm motivado o intenso fenômeno migratório atual, considerado o maior desde a Segunda Guerra Mundial, de acordo com dados da Anistia Internacional e da Comissão Europeia.

É o caso de inúmeras pessoas que, em tentativas desesperadas para fugir da violência e da pobreza em seus países de origem, têm buscado abrigo e refúgio, principalmente, na região da União Europeia, deixando em evidência para o mundo que as desigualdades e a falta de oportunidades deixaram de ser apenas preocupação da política interna de cada Estado, mas configuram-se questões

3 Artigo 1º da Constituição Federal - A República Federativa do Brasil, formada pela união indissolúvel dos Estados e Municípios e do Distrito Federal, constitui-se em Estado Democrático de Direito e tem como fundamentos:

I - a soberania;

II - a cidadania;

III - a dignidade da pessoa humana;

IV - os valores sociais do trabalho e da livre iniciativa; e

V - o pluralismo político.

Parágrafo único - Todo o poder emana do povo, que o exerce por meio de representantes eleitos ou diretamente, nos termos desta Constituição (Brasil, 2000). 
transnacionais, segundo o entendimento de Fraser (2008, 2009), que exigem solidariedade e participação ativa de toda a humanidade, por intermédio de governos comprometidos com o bem social, acima de qualquer interesse meramente material, seja econômico e/ou político.

Nesse processo migratório desenfreado, vemos os países de destino extremamente preocupados com a recepção e acomodação do elevado número de imigrantes. De uma maneira geral, essa preocupação diz respeito às questões relativas à futura inserção dos imigrantes no mercado de trabalho local.

O Brasil também lida com a recepção de imigrantes, o que nos faz pensar sobre a questão da oferta de trabalho para esse grupo de pessoas em território nacional.

De acordo com a British Broadcasting Corporation (BBC Brasil) ${ }^{4}$ e a Agência da ONU para refugiados (ACNUR) ${ }^{5}$, dados do Comitê Nacional para os Refugiados (Conare) ${ }^{6}$ indicam que entre o mês de agosto de 2011 até o mesmo período de 2015, 2.077 imigrantes sírios receberam asilo por parte do governo brasileiro. Por essa razão, o Brasil é considerado hoje o país que mais recebe refugiados vindos da Síria. É o caso também dos imigrantes vindos do Haiti.A imigração de haitianos no Brasil foi intensificada a partir de janeiro de 2010, quando um terremoto de proporções devastadoras provocou mortes e destruição de grande parte do país. A partir de então, muitos haitianos perderam suas casas e meios de subsistência, o que agravou em muito o já profundo estado de pobreza vivenciado pela população. Buscando trabalho e, consequentemente, melhores condições de vida, um alto número de pessoas emigrou do Haiti, vindo buscar asilo em terras brasileiras.

Portanto, ressaltamos que a integração de imigrantes e/ou refugiados é, para todos, um desafio a ser enfrentado, tanto na esfera cultural quanto econômica. Nos referimos aqui à adoção de medidas transformativas (remédios), nos termos propostos por Fraser (2007, 2008, 2009), que considerem as questões políticas contemporâneas a partir de uma perspectiva multidimensional, atreladas à cultura e à economia, que têm, cada vez mais, reflexos transnacionais e, nesse sentido, afetam indivíduos em diferentes partes do planeta.

Dentre tais medidas transformativas, a reorganização estrutural do acesso e da manutenção no mercado de trabalho é, indubitavelmente, uma via de acesso para o enfrentamento da pobreza, que ressalta relações sociais profundamente assimétricas, injustas e excludentes.

Estudo do Instituto de Pesquisa Econômica Aplicada (IPEA), publicado em setembro de 2015, apontou que em uma década (do 2000 a 2010) houve no Brasil um decréscimo de 27\% no chamado Índice de Vulnerabilidade Social (IVS), considerado uma forma de medir a exclusão social da população. Tal estudo afirma que esse índice passou de alto $(0,446)$ para médio $(0,326)$, sendo que o item em que houve maior redução da vulnerabilidade social foi o relativo à renda e ao trabalho. De acordo com os pesquisadores do IPEA, esse resultado é reflexo da redução do trabalho informal, do trabalho infantil e do aumento da taxa de ocupação laboral por parte da população durante o período pesquisado.

No entanto, essa boa notícia vem acompanhada de uma realidade social mais atual, que não ratifica o estudo do IPEA integralmente. Hoje, pouco mais de seis anos após o período final

4 Fonte:http://www.bbc.com/portuguese/noticias/2015/09/150904_brasil_refugiados_sirios_comparacao_internacional_lgb (12 setembro 2015)

5 Fonte: http:/www.acnur.org/portugues/recursos/estatisticas/dados-sobre-refugio-no-brasil/ (10 maio 2016)

6 O Comitê Nacional para os Refugiados (Conare) é um órgão colegiado, vinculado ao Ministério da Justiça, que reúne segmentos representativos da área governamental, da sociedade civil e da Organização das Nações Unidas (ONU), para:- analisar o pedido sobre o reconhecimento da condição de refugiado;

- deliberar quanto à cessação ex officio ou mediante requerimento das autoridades competentes da condição de refugiado;

- declarar a perda da condição de refugiado;

- orientar e coordenar as ações necessárias à eficácia da proteção, assistência, integração local e apoio jurídico aos refugiados, com a participação dos Ministérios e instituições que compõem o Conare; e

- aprovar instruções normativas que possibilitem a execução da Lei nº 9.474, de 22 de julho de 1997. 
pesquisado, o Brasil enfrenta dificuldades profundas nos âmbitos econômico, político e social. Especialmente na questão do mercado de trabalho, o momento atual está altamente fragilizado, expondo uma situação na qual um grande percentual da população sofre as agruras do desemprego, da exploração e da má remuneração, dentre outras.

Levando todas essas questões em consideração, resta certo que o trabalho é ponto central a ser considerado em situações diversas relativas aos diferentes grupos sociais.

Em variados contextos e cenários da sociedade, os indivíduos encontram no acesso ao mercado de trabalho e no exercício laboral, meios de inclusão social por intermédio da participação socioeconômica e do alcance da autonomia. Por essa razão, o estudo sobre grupos sociais e trabalho mostra-se absolutamente relevante.

\section{A participação das mulheres no mercado de trabalho}

Dentre tais grupos, entendemos que as mulheres têm enfrentado, mais diretamente, preconceitos e discriminações no mercado de trabalho, fato que provoca nosso interesse em refletir sobre o assunto.

No campo da Psicologia Social, autores como Aronson, Wilson e Akert (2002) entendem que o sexismo institucionalizado opera em toda a estrutura da sociedade. Nesse sentido, "uma manifestação extremamente interessante de estereotipagem ocorre na percepção das diferenças de gênero" (p. 296).

Uma das formas evidentes de expressão do fenômeno da estereotipagem dos gêneros é a divisão sexual do trabalho entendida como forma de organização que separa as atividades laborativas entre masculinas e femininas.

Nesse sentido, concordamos com a professora D'Ávila Neto (1994) quando afirma que "a evolução dos papéis no Brasil não se fez em ruptura com o passado patriarcal, mas conservou profundas raízes dele, o que se evidencia ainda numa rígida estereotipia, como, por exemplo, a de carreiras femininas x masculinas" (p. 55).

Em artigo publicado sobre a globalização e as mulheres no mercado de trabalho, D’Ávila Neto e Nazareth (2005) apontam que a discriminação enfrentada pelas mulheres nesse cenário social reflete, muitas vezes, estereótipos relativos aos discursos construídos e fortalecidos pelo patriarcalismo, no sentido de que as mulheres têm natureza própria para os cuidados com os filhos, família e atividades domésticas, consideradas pelas autoras um trabalho invisível, em razão de ser altamente desvalorizado.

Por essa razão, às mulheres seriam devidos trabalhos que, mesmo produtivos, estão relacionados à maternidade e outros típicos do "mundo feminino", segundo uma visão amplamente estereotipada.

Nessa perspectiva, as autoras ressaltam que, tanto no Brasil como em outros países da América Latina, o patriarcalismo rural deixou marcas significativas na atual sociedade, na qual esse rastro machista ainda vigora, de maneira muito expressiva, no mercado de trabalho.

Assim sendo, um dos resultados daí advindo é um quadro de abuso e violência psicológica em relação às mulheres, claramente identificado na divisão sexual do trabalho, na qual o androcentrismo prevalece.

Nessa perspectiva, cabem às mulheres, de uma maneira geral, os trabalhos mais precários e pior remunerados, quando comparados aos trabalhos dos homens. Embora a participação feminina no mercado de trabalho seja bastante expressiva, a diferença salarial em desfavor das mulheres também prevalece.

D'Ávila Neto e Nazareth (2005) ressaltam que o processo de globalização, considerado uma das causas do aumento do trabalho remunerado para as mulheres, as atinge de maneira 
diversificada, em razão das muitas condições diferenciadas entre elas, tais como: cultura, condição econômica, raça, acesso à educação e ao desenvolvimento tecnológico, dentre outras. Por essa razão, quando tais contextos não são valorizados, a sociedade globalizada apenas fortalece as diferenças e gera novas desigualdades.

No entendimento das autoras, as tradicionais questões de gênero, tais como a discriminação no mercado de trabalho, a má remuneração e o desemprego, dentre tantas outras, afetam, ainda mais diretamente, as mulheres chefes de família monoparental em situação de pobreza, configurando, assim, muito mais um problema social do que apenas um problema feminino.

No Brasil, o fenômeno da feminização da pobreza diz respeito, majoritariamente, às mulheres negras, conforme destacam D'Ávila Neto e Nazareth (2005), o que expõe que as questões de gênero e raça estão intimamente interligadas na nossa cultura como produto de um passado patriarcal e escravocrata.

As autoras enfatizam a relação entre aumento da pobreza, mulheres e estrutura familiar, o que caracteriza um fenômeno conhecido por feminização da pobreza, que retrata "uma mudança nos níveis de pobreza partindo de um viés desfavorável às mulheres ou aos domicílios chefiados por mulheres" (Ferri, \& Duarte, 2014, p. 73).

Conforme apontam D'Ávila Neto e Nazareth (2005), do ponto de vista do mercado de trabalho e do sistema econômico, as mulheres são consideradas menos valorizadas do que os homens com base em ideias e conceitos eivados de discriminação, o que representa um processo de subalternidade, opressão e exclusão, ao qual as mulheres vêm sendo submetidas há um longo período de tempo.

De acordo com Nuernberg (2001) e Kergoat (2009), o que ainda existe é uma tendência em considerar o trabalho dos homens de valor superior ao das mulheres, resultando assim em menores remunerações destinadas a elas.

De uma maneira geral, as mulheres recebem menores remunerações em razão da combinação de diversas situações, tais como: maior taxa de absenteísmo ao trabalho, frequente indisponibilidade para viagens e mudanças de residência por exigência do cargo, e elevado número de interrupções em suas carreiras, o que ocorre por ocasião de gravidezes, por exemplo.

Visto que todas essas situações têm como causa os cuidados com os filhos e demais familiares, bem como com a manutenção da moradia, isto é, os afazeres domésticos, entendemos que a diferença salarial está amparada, essencialmente, em uma divisão sexual do trabalho amplamente machista, que insiste em valorizar estereótipos e discriminações, afastando os homens de uma participação igualitária no trabalho reprodutivo, isto é, no trabalho doméstico.

Nessa perspectiva, a divisão sexual do trabalho é produtora de desigualdades e tensões evidentes na conciliação de vida profissional e trabalho reprodutivo. Para Madalozzo, Martins e Shiratori:

a divisão sexual do trabalho não tem efeito somente no emprego e na participação diferenciada de homens e mulheres no mercado, mas também afeta a forma como essas relações se difundem na sociedade. A responsabilização da afetividade e do trabalho não remunerado para as mulheres se traduz na perpetuação das desigualdades de tratamento entre os gêneros" (Madalozzo, Martins, \& Shiratori, 2010, p. 551).

O acúmulo de atividades reprodutivas e produtivas mostra-se, muitas vezes, uma tarefa árdua. Essa dupla jornada de trabalho merece um olhar atento por parte da família, da sociedade e do poder público.

Seguindo essa linha de pensamento, estamos de acordo com Atal, Nopo e Winder (2009) quando, em estudo sobre as diferenças salariais em diferentes países da América Latina 
- denominado Novo século, velhas desigualdades: diferenças salariais de gênero e etnia na América Latina, publicado pelo Banco Interamericano de Desenvolvimento (BID) - apontam que, por parte do Estado, a oferta de creches e escolas com ensino de qualidade e horários estendidos são algumas das medidas viáveis para que as mulheres possam ter maior disponibilidade para o trabalho. No âmbito doméstico, uma divisão das tarefas de maneira mais equitativa é uma forma de enfrentamento da questão das disparidades salariais com base no gênero.

Sobre as disparidades salariais entre homens e mulheres, ressaltamos que a Dinamarca é o único país, dentre 142 pesquisados, no qual as mulheres têm remuneração superior à dos homens ${ }^{7}$, de acordo com o Relatório Anual das Diferenças de Gênero - 2014, divulgado pelo Fórum Econômico Mundial ${ }^{8}$.Com base nos dados dos últimos anos sobre a trajetória das diferenças salariais, esse relatório prevê que apenas no ano de 2095 poderá ser alcançada a igualdade de gênero na seara trabalhista, caso tal processo/fenômeno mantenha-se nas mesmas bases.

No entanto, sendo mais otimistas, ressaltamos que medidas transformativas consistentes podem acelerar o processo de paridade de gêneros no mercado de trabalho, configurando assim, relações mais simétricas e justas.

Nesse sentido, o documento final da IV Reunião da Cúpula das Américas', realizada na cidade argentina de Mar del Plata em 2005, aponta que a criação de empregos e o trabalho exercido em condições de igualdade significam desenvolvimento com paridade de oportunidades. No referido documento, representantes de vários países do continente americano discutiram o importante papel do Estado no enfrentamento do desemprego, destacando que a ideia nuclear diz respeito ao enfrentamento da pobreza por intermédio do trabalho.

Retomando a questão relativa às mulheres, nos referimos à Hirata (2001) quando aponta que, embora o cenário econômico e financeiro mundial tenha sido amplamente influenciado pelo processo de globalização, as ideias que dizem respeito à divisão sexual do trabalho não passaram por modificações estruturais e/ou significativas. Para a autora, a carga de trabalho doméstico ainda está, majoritariamente, destinada exclusivamente às mulheres, favorecendo um quadro de desigualdades profundas em desfavor destas. Como corolário, as diferenças salariais tornam-se demonstrações claras de relações nas quais ainda prevalecem discriminações e estereótipos.

Embora a inserção das mulheres no mercado de trabalho exponha aspectos negativos tais como diferenças salarias com bases discriminatórias, há, por outro lado, uma questão manifestamente relevante e positiva: trata-se da autonomia adquirida pelas mulheres por intermédio do exercício laboral.

Nessa seara, destacamos o fato de que o trabalho pode ser considerado uma via de acesso à autonomia, promovendo meios para que as mulheres alcancem "habilidade de construir objetivos e valores próprios, liberdade de fazer escolhas e planos, e agir em conformidade com tais valores e objetivos" (Rosenfield, \& Alves, 2011, p. 211).

Sobre o assunto, ressaltamos que Fraser (2001, 2013), em sua teoria da justiça social, contribui sobremaneira para a compreensão do processo de construção da autonomia - em seus aspectos econômicos, culturais e políticos - por intermédio da participação paritária no âmbito socioeconômico, uma vez que a autonomia pressupõe o reconhecimento, por parte das mulheres, de pertencimento ao grupo, à coletividade.

7 Na Dinamarca, o salário médio das mulheres equivale a 103\% do salário médio dos homens.

8 O Fórum Econômico Mundial é uma organização internacional sediada em Genebra, na Suíça, responsável pela organização de encontros anuais com a participação de líderes políticos nacionais, presidentes, chefes de Estado, ministros, dirigentes de Bancos Centrais, executivos de corporações, intelectuais e demais personalidades de destaque na área socioeconômica e empresarial. (Recuperado de http://www12.senado.leg.br/noticias/entenda-o-assunto/forum-economico-mundial, 17 agosto 2015)

9 A Cúpula das Américas é uma reunião entre os chefes de Estado dos países localizados no continente americano, criada pela Organização dos Estados Americanos (OEA), a fim de promover maior grau de cooperação econômica entre os países participantes. 
Assim sendo, a autonomia está relacionada à capacidade e oportunidade para tomada de decisões de maneira independente, o que leva as mulheres a ocupar posições em arenas na quais existam discussões, debates e escolhas a serem feitas com a participação popular.

Levando em consideração todo o fenômeno de construção da autonomia, a questão das mulheres no mercado de trabalho indica uma certa superação de espaços nos quais ainda persiste a hegemonia masculina, o que é considerado nos estudos de Siqueira (2002).

Sobre a questão da autonomia relacionada às mulheres, Gurgel (2004) no diz que:

Ao longo do tempo, a noção de autonomia, para o feminismo, passou por importantes ressignificações, chegando a desfigurar-se no enfrentamento com a questão do Estado. Sua abordagem deve levar em consideração pelo menos três aspectos: a noção de liberdade, o reconhecimento da opressão e a ação coletiva das mulheres, como elementos que conferem um nexo interno às variadas dimensões ontológicas dos sujeitos de ação da práxis feminista (Gurgel, 2004, p. 100).

A autonomia econômica, alcançada em diferentes níveis conforme o valor financeiro oferecido em contraprestação ao trabalho, é uma forma de controle de recursos materiais, o que reflete na habilidade para produzir relações sociais mais igualitárias e participativas.

Nesse caso, a autonomia das mulheres passa pela geração de renda e, sobretudo, pelo exercício do trabalho formalizado e remunerado dignamente.

Estamos nos referindo, portanto, ao trabalho decente, nos termos propostos pela Organização Internacional do Trabalho (OIT), agência multilateral ligada à ONU, formada por representantes dos Estados-membros, das organizações de empregados e de empregadores.

\section{O trabalho decente de acordo com a OIT}

A OIT, criada no ano de 1919 a fim de formular e aplicar normas internacionais do trabalho por intermédio de convenções, recomendações e resoluções ${ }^{10}$, teve como primado o conceito/ concepção de que a paz mundial contínua somente seria estabelecida com base na justiça social.

A partir desse pressuposto, portanto, a ideia de trabalho decente vem atrelada aos preceitos de justiça social, segundo Fraser (2007, 2009, 2013) e Reis (2010).

O Brasil é um dos países fundadores da OIT e tem feito parte das Conferências Internacionais do Trabalho desde a primeira reunião. Trata-se de reuniões anuais, realizadas pela OIT, nas quais são elaborados os documentos (convenções, recomendações e resoluções) relativos ao trabalho.

Valorizando a questão da justiça social em paralelo ao trabalho, especialmente para as mulheres, ressaltamos que a OIT tem importante atuação nos âmbitos econômico, social e político, ratificando, dessa maneira, a ideia de que o enfrentamento efetivo das discriminações, abusos e desigualdades no mercado de trabalho só será possível a partir do trabalho decente.

Formulado em 1999 pela OIT, o conceito de trabalho decente diz respeito à promoção de oportunidades para o exercício de um "trabalho adequadamente remunerado, exercido em condições de liberdade, equidade e segurança, capaz de garantir uma vida digna” (Barzotto, 2010, p. 1).

10 As convenções constituem-se de tratados multilaterais abertos à ratificação dos Estados-membros, que, uma vez ratificados, devem integrar a respectiva legislação nacional. Já as recomendações se destinam a sugerir normas que podem ser adotadas por qualquer das fontes diretas ou autônomas do Direito do Trabalho, embora visem, basicamente, ao legislador de cada um dos países vinculados à OIT. No entendimento dos autores, a convenção e a recomendação não são, materialmente, distintas. A diferença está no fato de que a convenção requer a ratificação do Estado-membro e a recomendação precisa ser submetida à autoridade do país para que se possa legislar sobre a matéria em tela. As resoluções não vinculam o Estado-membro, apenas sugerem aos organismos internacionais e aos Estados-membros que adotem determinados posicionamentos de acordo com os princípios da OIT (Süssekind, Maranhão, Vianna, \& Teixeira Filho, 2011, p. 148). 
De acordo com a OIT, o trabalho decente é considerado o ponto de convergência de seus quatro objetivos estratégicos ${ }^{11}$, quais sejam:

1 - o respeito aos direitos no trabalho (em especial aqueles definidos como fundamentais pela Declaração Relativa aos Direitos e Princípios Fundamentais no Trabalho e seu seguimento, adotada em 1998, quais sejam: liberdade sindical e reconhecimento efetivo do direito de negociação coletiva, eliminação de todas as formas de trabalho forçado, abolição efetiva do trabalho infantil, e eliminação de todas as formas de discriminação em matéria de emprego e ocupação;

2 - a promoção do emprego produtivo e de qualidade;

3 - a extensão da proteção social;

4 - o fortalecimento do diálogo social.

Nesse sentido, o conceito de trabalho decente está atrelado à superação do estado de pobreza, ao decréscimo de desigualdades sociais, ao desenvolvimento sustentável e à garantia de governabilidade em bases democráticas, conforme nos apontam Azevedo Neto (2015) e Brito Filho (2013).

Em maio de 2006, o governo brasileiro lançou a chamada Agenda Nacional de Trabalho Decente (ANTD), cujas prioridades dizem respeito à geração de empregos de maneira igualitária, à erradicação dos trabalhos escravos e infantil, e ao fortalecimento do diálogo social entre governo, empregadores e trabalhadores.

A ideia, portanto, é reiterar que o trabalho decente é parte essencial do processo de desenvolvimento econômico e social, ancorado na justiça social, na igualdade de oportunidades e no respeito aos princípios democráticos.

Nesse cenário, grupos minoritários e/ou subalternos encontram possibilidades de alcançar e garantir, por intermédio do exercício do trabalho, meios de inclusão e participação socioeconômica.

Dentre esses grupos, destacamos a posição das mulheres no mercado de trabalho. Embora essa ainda seja uma questão cerceada por discriminações, preconceitos e estereótipos, o Brasil foi considerado destaque no relatório denominado Progresso das Mulheres no Mundo 2015-2016: Transformar as economias para realizar os direitos, publicado em abril de 2015 pela ONU Mulheres, entidade da ONU para a igualdade de gênero e o empoderamento das mulheres.

O relatório em tela afirma a concepção de que os países devem ter como prioridade a efetividade de medidas corretivas e transformativas das desvantagens socioeconômicas enfrentadas pelas mulheres.

Nesse documento, o Brasil é reconhecido pela criação do trabalho decente para as mulheres, em adição a investimentos em programas sociais e políticas públicas destinadas às mulheres, favorecendo, assim, uma maior participação feminina na vida social e econômica do país, segundo Santos (2014). De acordo com o conteúdo do relatório, as decisões políticas nesse sentido, fomentaram possibilidades para o alcance do empoderamento feminino e de uma maior igualdade de direitos entre homens e mulheres.

Vemos, assim, que a ideia de desenvolvimento está assentada na promoção do trabalho decente, no âmbito da justiça social.

Dentre os diferentes programas sociais direcionados às mulheres, destacamos o atual Mulher, Viver sem Violência, coordenado pela Secretaria de Políticas para as Mulheres da Presidência da República, que prevê a criação da chamada Casa da Mulher Brasileira, espaço no qual estão sendo implantados serviços para atendimento das mulheres vítimas de violência. A intenção do poder público é oferecer para essas mulheres assistência e atendimento policial, jurídico, psicológico,

11 Fonte: http://www.oitbrasil.org.br/content/o-que-e-trabalho-decente (16 julho 2015). 
moradia temporária e encaminhamento para o mercado de trabalho, a fim de fomentar/favorecer/ promover a autonomia financeira de cada uma delas.

Nadine Gasman, representante da ONU Mulheres no Brasil, considera que "em escala de abrangência, pelo tamanho do Brasil e pela implementação em todos os estados, essa ação não tem precedentes", por se tratar de uma forma de enfrentamento multidimensional da violência contra as mulheres, de maneira eficiente e levando em consideração "a integração e a humanização dos serviços públicos" (ONU Mulheres, 2015, p. 1).

Baltar (2013) aponta que o trabalho decente está de acordo com políticas de desenvolvimento que valorizam questões sociais, em observância aos direitos já adquiridos pelos trabalhadores.

A OIT delibera por intermédio de convenções com natureza jurídica de tratados internacionais. De acordo com o processo de internacionalização legislativa brasileiro, as convenções tornam-se decretos, seguindo os mesmos trâmites que os tratados internacionais ${ }^{12}$. Por intermédio destes decretos, há a ratificação e a promulgação do documento, gerando, assim, efeitos no âmbito nacional, como norma interna.

De acordo com entendimento da OIT, as convenções estão divididas em fundamentais, de governança e técnicas ${ }^{13}$.

As oito convenções fundamentais, que integram a Declaração da OIT sobre os Princípios e Direitos Fundamentais no Trabalho ${ }^{14}$, são as seguintes:

- 29: sobre o trabalho forçado - de 1930 e ratificada pelo Brasil em 1957;

- 87: sobre a liberdade sindical e a proteção do direito sindical - de 1948, não ratificada pelo Brasil;

- 98: sobre o direito de sindicalização e de negociação coletiva - de 1949 e ratificada pelo Brasil em 1952;

- 100: sobre a igualdade de remuneração - de 1951, ratificada pelo Brasil em 1957;

- 105: sobre a abolição do trabalho forçado - de 1957, ratificada pelo Brasil em 1965;

- 111: sobre a discriminação no âmbito do emprego e da profissão - de 1958, ratificada pelo Brasil em 1965;

- 138: sobre a idade mínima para a admissão ao trabalho - de 1973 e ratificada pelo Brasil em 2001;

- 182: sobre a proibição das piores formas de trabalho infantil e ação imediata para a sua eliminação - de 1999 e ratificada pelo Brasil em 2000.

Ressaltamos que apenas a convenção 87 ainda não foi ratificada e promulgada pelo Brasil, que, até o momento adota o Princípio da Unicidade Sindical ${ }^{15}$, pelo qual está vedada a pluralidade de sindicatos, prevista na referida convenção, isto é, a existência de mais de uma entidade representativa de categoria profissional ou econômica dentro da mesma base territorial, conforme nos aponta Nascimento (2011).

Sobre as mulheres no mercado de trabalho, destacamos as convenções de número 100, que indica a igualdade de remuneração e de benefícios entre homens e mulheres, por trabalho de igual valor; e a de número 111, que sugere a formulação de uma política nacional que elimine toda

12 O exame da vigente Constituição Federal (CF) permite constatar que a execução dos tratados internacionais e a sua incorporação à ordem jurídica interna decorrem, no sistema adotado pelo Brasil, de um ato subjetivamente complexo, resultante da conjugação de duas vontades homogêneas: a do Congresso Nacional, que resolve, definitivamente, mediante decreto legislativo, sobre tratados, acordos ou atos internacionais (CF, art. 49, I) e a do Presidente da República, que, além de poder celebrar esses atos de direito internacional (CF, art. 84, VIII), também dispõe - enquanto chefe de Estado que é - da competência para promulgá-los mediante decreto. (ADI 1.480-MC, rel. min. Celso de Mello, julgamento em 4/9/1997, Plenário, DJ de 18/5/2001. Recuperado de https:// goo.gl/8qIxHJ, 09 agosto 2015).

13 Recuperado de https://goo.gl/DKylvb. (14 agosto 2015)

14 Declaração de Princípios Fundamentais e Direitos no Trabalho da OIT (1998). Fonte: http://www.ilo.org/public/english/standards/ declaration/declaration_portuguese.pdf (13 julho 2015)

15 Constituição Federal de 1988, artigo 8º, inciso II. 
discriminação em matéria de emprego, formação profissional e condições de trabalho por motivos de raça, cor, sexo, religião, opinião política, ascendência nacional ou origem social, e promoção da igualdade de oportunidades e de tratamento. Tais convenções tratam, mais diretamente, de questões relativas às mulheres no mercado de trabalho.

De acordo com Ariosi (2004), há quatro convenções de governança consideradas prioritárias para o exercício "da maneira pela qual o poder é exercido na administração dos recursos sociais e econômicos de um país visando o desenvolvimento e a capacidade dos governos de planejar, formular e programar políticas e cumprir funções” (Banco Mundial, 2007, p. 17). São elas:

- 81: sobre a manutenção de um sistema de inspeção do trabalho nas indústrias, no comércio e na agricultura - de 1947, ratificada pelo Brasil em 1989;

- 122: sobre o estabelecimento de uma política ativa para promover o emprego, estimulando o crescimento econômico e o aumento dos níveis de vida - de 1964, ratificada pelo Brasil em 1969;

- 129: sobre a manutenção de um sistema de inspeção do trabalho nas indústrias, no comércio e na agricultura - de 1969, não ratificada pelo Brasil;

- 144: sobre a consulta efetiva entre representantes do governo, dos empregadores e dos trabalhadores a respeito das normas internacionais do trabalho - de 1976 e ratificada pelo Brasil em 1994.

As demais convenções, denominadas técnicas de acordo com a OIT, são alocadas em doze categorias a partir de diferentes temas: direitos humanos básicos, emprego, políticas sociais, administração do trabalho, relações industriais, condições de trabalho, segurança social, emprego de mulheres, emprego de crianças e jovens, trabalhadores migrantes, trabalhadores indígenas e outras categorias especiais.

\section{Considerações finais}

Embora a participação das mulheres no mercado de trabalho reflita, muitas vezes, uma cultura marcada, precipuamente, por atitudes e comportamentos androcêntricos - que embasam legislações e regulamentos acerca da presença feminina no cenário laborativo, provocando estereótipos, discriminações e preconceitos - é inegável a importância socioeconômica do exercício laboral, conforme nos apontam Hirata e Zarifian (2009).

Por essa razão, entendemos que o comprometimento do poder público com a garantia de acesso igualitário ao trabalho é um dos pilares da justiça social e via segura de inclusão social e econômica, conforme os conceitos propostos por Fraser (2007, 2009, 2013).

Nessa perspectiva, nos referimos à promoção de uma economia com características mais solidárias e cooperativas, o que não significa uma afronta ao capitalismo, mas um caminho possível de coexistência entre interesses materiais e dignidade humana.

O crescimento econômico, por si só, não assegura o desenvolvimento social de um Estado. $\mathrm{O}$ combate à pobreza, à exploração e às desigualdades excludentes exigem medidas profundamente transformativas, por intermédio de políticas públicas ancoradas em princípios democráticos inclusivos e, essencialmente, humanizados.

Nos referimos, portanto, a um formato de capitalismo que não considere o trabalho apenas como um modo de exploração máxima, no qual o lucro esteja posto acima de qualquer bem-estar do trabalhador, mas no qual a solidariedade e a cooperação caminhem juntas com o desenvolvimento econômico. 
A exploração do trabalho humano é uma das formas mais degradantes de violência às pessoas, e a desvalorização do trabalho configura uma das mazelas ainda enfrentada muito diretamente pela humanidade.

Nesse cenário, o trabalho decente, nos termos propostos pela OIT, mostra-se uma forma de enfrentamento das dificuldades vivenciadas por aqueles que encontram no exercício laboral uma afronta aos seus direitos e à dignidade humana.

A questão das mulheres no mercado de trabalho encontra, na promoção do trabalho decente, um caminho de (re)construção de pontes de acesso à participação social e econômica de uma maneira mais ampla e igualitária.

Cada vez mais, levando em consideração o sistema econômico capitalista absolutamente globalizante, um pretendido cenário de justiça social deve estar, sem dúvida, em consonância com os princípios e os conceitos que embasam o trabalho decente.

Em entrevista, José Alberto Mujica Cordano, ex-presidente uruguaio, manifestou-se dizendo que:

Não se pode dizer que não há recursos. Não há governança política. Os governos se preocupam somente com as próximas eleições, quem vai se sentar no trono. A gente briga pelo poder e esquece o povo, os problemas mundiais. Não existe crise ecológica, mas política. Chegamos a uma fase da civilização que exige acordos planetários. Mas viramos os olhos. Nos prendemos a nacionalismos e a questões de potência nacional, sobretudo os países mais fortes, que deveriam dar exemplo (Human, 2015).

Nesse sentido, reiteramos a ideia de que o trabalho é a base da justiça social, que deve ser considerada a partir da tridimensionalidade proposta por Fraser (2007, 2008, 2009, 2013): nos âmbitos econômico, social e político, a partir do entendimento de que essa é uma questão transnacional, uma vez que diz respeito aos direitos humanos como um todo. Discriminações, preconceitos e estereótipos retratam repressões, dominações e assimetrias profundas no mercado de trabalho, cujas razões não devem encontrar respaldo em um ambiente de justiça e liberdade social.

\section{Referências}

Ariosi, M. F. (2004). Os efeitos das convenções e recomendações da OIT no Brasil. Jus Navigandi, 9 (507).

Aronson, E., Wilson, T. D., \& Akert, R. M. (2002). Psicologia social. Rio de Janeiro: LTC.

Atal, J. P., Nopo, H., \& Winder, N. (2009). New century, old disparities: gender and ethnic wage gaps in Latin America. InterAmerican Development Bank. Department of Research and Chief Economist.

Azevedo Neto, P. T. (2015). O trabalho decente como um direito humano. São Paulo: LTr.

Baltar, R. (2013). Desenvolvimento, globalização e trabalho decente. Caderno CRH, 26 (67), 105-122.

Banco Mundial (2007). Governança no Sistema Único de Saúde (SUS) do Brasil: melhorando a qualidade do gasto público e gestão de recursos. Relatório n⿳0 36601-BR. Washington, DC.

Barzotto, L. C. (2010). Trabalho decente: dignidade e sustentabilidade. Âmbito Jurídico, 13 (78).

Brasil (2000). Constituição da República Federativa do Brasil de 1988 (16aㅡ ed.). São Paulo: Atlas.

Brito Filho, J. C. M. (2013). Trabalho decente: análise jurídica da exploração do trabalho. Trabalho escravo e outras formas de trabalho indigno. São Paulo: LTr.

D’Ávila Neto, M. I. (1994). O autoritarismo e a mulher: o jogo da dominação macho-fêmea no Brasil. Rio de Janeiro: Artes $\&$ Contos.

D’Ávila Neto, M. I., \& Nazareth, J. (2005). Globalization and women's employment. Peace Review: a Journal of Social Justice, 17 (3), 215-220. 
Ferri, C., \& Duarte, R. C. P. (2014). Feminização da pobreza e meio ambiente do trabalho. Sociedade em Debate, 20 (2), 63-85.

Fraser, N. (2001). Da redistribuição ao reconhecimento? Dilemas da Justiça na era pós-socialista. In J. Souza (Org.), Democracia hoje: novos desafios para a teoria democrática contemporânea (pp. 245-282). Brasília: UnB.

Fraser, N. (2013). Justiça anormal. Revista da Faculdade de Direito da Universidade de São Paulo, 108, 739-768.

Fraser, N. (2009). O feminismo, o capitalismo e a astúcia da História (Dossiê: Contribuições do pensamento feminista para as Ciências Sociais). Mediações, 14 (2), 11-33.

Fraser, N. (2007). Reconhecimento sem ética? Lua Nova, 70, 101-138.

Fraser, N. (2008). Social rights and gender justice in the neoliberal moment: A conversation about welfare and transnational politics. Feminist Theory, 9 (2), 225-245.

Gurgel, T. (2004). Feminismo e liberdade. Universidade e Sociedade, 14 (43), 99-109.

Hirata, H. (2001). Globalização e divisão sexual do trabalho. Cadernos Pagu, 18 (2), 139-156.

Hirata, H., \& Zarifian, P. (2009). Trabalho (o conceito de). In H. Hirata, H. Françoise Laborie, \& D. S. Le Doaré (Orgs.), Dicionário crítico do feminismo (pp. 251-252). São Paulo: Unesp.

Human (2015). Entrevista com José Alberto Mujica Cordano. Direção: Yann Arthus-Bertrand. Produção: Bettencourt Schueller Foundation, GoodPlanet Foundation. Recuperado de https://goo.gl/u3uE4Y [12 setembro 2015]

Kergoat, D. (2009). A divisão sexual do trabalho. In H. Hirata, H. Françoise Laborie, \& D. S. Le Doaré (Orgs.), Dicionário crítico do feminismo (pp. 67-68). São Paulo: Unesp.

Madalozzo, R., Martins, S. R., \& Shiratori, L. (2010). Participação no mercado de trabalho e no trabalho doméstico: homens e mulheres têm condições iguais? Estudos Feministas, 18 (2), 547-566.

Nascimento, A. M. (2011). Curso de direito do trabalho. História e teoria geral do direito do trabalho: relações individuais e coletivas do trabalho. São Paulo: Saraiva.

Nuernberg, A. H. (2001). Uma análise crítica do direito à diferença. Estudos Feministas, 9 (1), 299-301.

ONU Mulheres (2015). Casa da Mulher Brasileira. Recuperado de http://www.onumulheres.org.br [11 agosto 2015]

Reis, J. T. (2010). Trabalho decente. Âmbito Jurídico, 76.

Rosenfield, C. L., \& Alves, D. A. (2011). Autonomia e trabalho informacional: o teletrabalho. Dados - Revista de Ciências Sociais, 54 (1), 207-233.

Santos, Y. G. dos (2014). As mulheres como pilar da construção dos programas sociais. Caderno CRH, 27 (72),479-494. Siqueira, M. J. T. (2002). Sobre o trabalho das mulheres: contribuições segundo uma analítica de gênero. Revista Psicologia Organizações e Trabalho, 2 (1), 11-30.

Süssekind, A. L., Maranhão, D., Vianna, J. S., \& Teixeira Filho, J. L. (2011). Instituições de direito do trabalho. São Paulo: Editora LTr.

\section{Endereço para correspondência}

claudiacolcerniani@hotmail.com,inadavila@gmail.com,

Recebido em: 17/11/2015

claudiocavas@gmail.com

Revisado em: 02/12/2016

Aprovado em: 02/12/2016 